\title{
Editorial \\ GIS and Remote Sensing for Renewable Energy Assessment and Maps
}

\author{
Benedetto Nastasi $^{1, *(\mathbb{D})}$ and Meysam Majidi Nezhad ${ }^{2}$ (D) \\ 1 Department of Planning, Design and Technology of Architecture, Sapienza University of Rome, \\ Via Flaminia 72, 00196 Rome, Italy \\ 2 Department of Astronautics, Electrical and Energy Engineering (DIAEE), Sapienza University of Rome, \\ 00184 Rome, Italy; meysam.majidinezhad@uniroma1.it \\ * Correspondence: benedetto.nastasi@outlook.com
}

check for updates

Citation: Nastasi, B.; Majidi Nezhad, M. GIS and Remote Sensing for Renewable Energy Assessment and Maps. Energies 2022, 15, 14. https:// doi.org/10.3390/en15010014

Received: 23 November 2021 Accepted: 11 December 2021 Published: 21 December 2021

Publisher's Note: MDPI stays neutral with regard to jurisdictional claims in published maps and institutional affiliations.

Copyright: (C) 2021 by the authors. Licensee MDPI, Basel, Switzerland. This article is an open access article distributed under the terms and conditions of the Creative Commons Attribution (CC BY) license (https:// creativecommons.org/licenses/by/ $4.0 /)$.

\section{Overview of the Articles in This Special Issue}

Geographic Information Systems (GIS) and Remote Sensing (RS) techniques are of great interest for the renewable energy field. The assessment and monitoring of Renewable Energy Sources (RESs) potential is critical in planning their high-penetration in the energy systems. To this aim, several different measurements tools such as in-situ measurements (cup anemometers and buoys), on-site RS tools (e.g., LIDAR and SODAR), satellite image data and reanalysis datasets (e.g., ECMWF and MERRA) can be used.

This Special Issue aims to provide the state-of-the-art tools mentioned earlier in different energy applications and at different scales, i.e., urban, regional, national and even continental, for planning and policymaking of renewable scenarios. For this purpose, the Special Issue "GIS and Remote Sensing for Renewable Energy Assessment and Maps" has been designed and launched, intended for renewable energy engineers, GIS and platform users, as well as planners. Among a very high number of submissions, 13 articles were selected for acceptance and publication.

The first paper by Jie et al. [1] presents a deep convolutional neural network to automatically extract distributed photovoltaic power stations from high-resolution RS images automatically and efficiently. In addition, a gated fusion module was introduced based on a semantic segmentation model with an encoder-decoder structure to address the problem that small photovoltaic panels are challenging to identify.

The following paper by Spyridonidou et al. [2] develops an innovative sustainable spatial energy planning framework at a national scale for identifying and prioritizing appropriate, technically and economically feasible, environmentally sustainable and socially acceptable sites for the siting of large-scale Onshore Wind Farms (OWFs) and Photovoltaic Farms (PVFs).

The third paper in this Special Issue, by Riva Sanseverino et al. [3], estimates the life-cycle land-use requirement for PV development to provide scientific-based evidence for policymakers on the quantity of land required so that the land budget can be suitably allocated.

The following paper by Bhavya Kausika and van Sark [4] focuses on atmospheric input parameters using calibration and validation of the solar radiation model developed in GIS where emission and transmissibility have also been investigated. The results show that the default values of the emission and transmission model lead to underestimation or overestimation of solar radiation.

The next paper by Coelho Vieira da Costa et al. [5] identifies existing PV solar plants using semantic segmentation and a mosaicking approach for large image classification. The authors compared four architectures (U-net, DeepLabv3+, Pyramid Scene Parsing Network, and Feature Pyramid Network) with four backbones (Efficient-net-b0, Efficient-net-b7, ResNet-50, and ResNet-101). 
The sixth paper of this Special Issue, by Alcalá et al. [6], proposes a method for automated assessment of Small Hydro-Power (SHP) potential for a run-of-river (RoR) scheme using GIS. Results showed that the headrace's length represented a significant contribution to hydro-power potential estimation.

In the next paper, Kokkos et al. [7] utilize the six-hourly data of wind speed for the period between 2011 and 2019, as retrieved from the Copernicus Marine Environmental Service (CMEMS), to map the Thracian Sea. This study involved descriptive statistics on wind speed and direction data; frequency distributions of daily-mean wind speeds per wind direction sector; total wind energy content assessment per wind speed increment and sector, total annual wind energy production (MWh/year), wind power density, probability density function and Weibull wind speed distribution, together with the relevant dimensionless shape and scale parameters.

In the eighth paper, Heydari et al. [8] propose a combined forecasting model consisting of empirical mode decomposition, fuzzy group method of data handling neural network and grey wolf optimization algorithm. Furthermore, a combined K means and identifying density-based local outliers was applied to detect and clean the proposed forecasting model's raw supervisory control and data acquisition data. As a result, the proposed model by Heydari and et al. has higher accuracy than others in the literature and provides single and combined forecasting models in different time-steps ahead and seasons.

The ninth paper by Vaisi and et al. [9] presents an innovative monthly thermal energy mapping method to calculate and visualize heat demand accurately for various types of buildings. The method includes three consecutive phases: (i) calculating energy loss, (ii) completing a dataset that includes energy and building information, and (iii) generating the monthly heat demand maps for the community.

In the tenth paper, Diler Alemdar et al. [10] examined how the Covid-19 pandemic has affected Istanbul's traffic mobility and air quality. The authors observed, visualized, compared, and discussed the post- and pre-lockdown impact on Istanbul's traffic mobility and air quality. Various spatial analyses were performed in GIS with statistical data use. Thus, the environmental effects of the pandemic could be better observed. The results showed positive traffic mobility and air quality changes, especially in April-May. PM10, $\mathrm{SO}_{2}, \mathrm{CO}, \mathrm{NO}_{2}$ and $\mathrm{NO}_{x}$ parameter values improved by $21.21 \%, 16.55 \%, 18.82 \%, 28.62 \%$ and $39.99 \%$, respectively.

Barbarelli and Nastasi [11] in the eleventh paper classify and analyze expeditious evaluation methods to assist energy managers and system designers in dealing with tides and tidal currents. The most straightforward methods for future work plans are evaluated according to the geographical features of the site, which is supported by more complex and accurate on-site measurements and modeling.

In the twelfth paper, presented by Valenzuela-Dominguez and et al. [12], a mathematical model based on easy access to geographical and meteorological information to calculate the total solar radiation on the earth's surface is examined. The study's results were verified by statistical analysis and satellite estimates from the National Aeronautics and Space Administration (NASA). This practical approach and the results obtained for estimating solar radiation in other parts of the globe can be replicated without the need to read the meteorological stations on-site and thus reduce the cost of deciding on the location of solar energy collection equipment.

Finally, the last article presented by Quiroga-Ocaña and et al. [13] aims to calculate and evaluate the optimal angles of inclination and azimuth for a receiver surface using a mathematical model developed for the state of Mexico using a set of criteria. This study aims to identify the optimal performance to achieve the maximum possible solar radiation during the year for solar projects in the study area. The results show that this model can be used as a tool to accelerate decision-making in the design of solar harvest surfaces and allow the design of discrete tracking systems with an increase in solar energy harvest of more than $5 \%$ per year. 
Author Contributions: Conceptualization, B.N. and M.M.N.; writing-original draft preparation, B.N. and M.M.N.; writing-review and editing, B.N. and M.M.N. All authors have read and agreed to the published version of the manuscript.

Funding: This research received no external funding.

Conflicts of Interest: The authors declare no conflict of interests.

\section{References}

1. Jie, Y.; Ji, X.; Yue, A.; Chen, J.; Deng, Y.; Chen, J.; Zhang, Y. Combined Multi-Layer Feature Fusion and Edge Detection Method for Distributed Photovoltaic Power Station Identification. Energies 2020, 13, 6742. [CrossRef]

2. $\quad$ Spyridonidou, S.; Sismani, G.; Loukogeorgaki, E.; Vagiona, D.G.; Ulanovsky, H.; Madar, D. Sustainable Spatial Energy Planning of Large-Scale Wind and PV Farms in Israel: A Collaborative and Participatory Planning Approach. Energies 2021, $14,551$. [CrossRef]

3. Sanseverino, E.R.; Cellura, M.; Luu, L.Q.; Cusenza, M.A.; Nguyen Quang, N.; Nguyen, N.H. Life-Cycle Land-Use Requirement for PV in Vietnam. Energies 2021, 14, 861. [CrossRef]

4. Kausika, B.B.; van Sark, W.G.J.H.M. Calibration and Validation of ArcGIS Solar Radiation Tool for Photovoltaic Potential Determination in the Netherlands. Energies 2021, 14, 1865. [CrossRef]

5. Costa, M.V.C.V.d.; Carvalho, O.L.F.d.; Orlandi, A.G.; Hirata, I.; Albuquerque, A.O.d.; Silva, F.V.e.; Guimarães, R.F.; Gomes, R.A.T.; Júnior, O.A.d.C. Remote Sensing for Monitoring Photovoltaic Solar Plants in Brazil Using Deep Semantic Segmentation. Energies 2021, 14, 2960. [CrossRef]

6. Alcalá, G.; Grisales-Noreña, L.F.; Hernandez-Escobedo, Q.; Muñoz-Criollo, J.J.; Revuelta-Acosta, J.D. SHP Assessment for a Run-of-River (RoR) Scheme Using a Rectangular Mesh Sweeping Approach (MSA) Based on GIS. Energies 2021, $14,3095$. [CrossRef]

7. Kokkos, N.; Zoidou, M.; Zachopoulos, K.; Nezhad, M.M.; Garcia, D.A.; Sylaios, G. Wind Climate and Wind Power Resource Assessment Based on Gridded Scatterometer Data: A Thracian Sea Case Study. Energies 2021, 14, 3448. [CrossRef]

8. Heydari, A.; Majidi Nezhad, M.; Neshat, M.; Garcia, D.A.; Keynia, F.; De Santoli, L.; Bertling Tjernberg, L. A Combined Fuzzy GMDH Neural Network and Grey Wolf Optimization Application for Wind Turbine Power Production Forecasting Considering SCADA Data. Energies 2021, 14, 3459. [CrossRef]

9. Vaisi, S.; Mohammadi, S.; Habibi, K. Heat Mapping, a Method for Enhancing the Sustainability of the Smart District Heat Networks. Energies 2021, 14, 5462. [CrossRef]

10. Alemdar, K.D.; Kaya, Ö.; Canale, A.; Çodur, M.Y.; Campisi, T. Evaluation of Air Quality Index by Spatial Analysis Depending on Vehicle Traffic during the COVID-19 Outbreak in Turkey. Energies 2021, 14, 5729. [CrossRef]

11. Barbarelli, S.; Nastasi, B. Tides and Tidal Currents-Guidelines for Site and Energy Resource Assessment. Energies 2021, 14, 6123. [CrossRef]

12. Valenzuela-Domínguez, F.A.; Cruz, L.A.S.; Enríquez-Velásquez, E.A.; Félix-Herrán, L.C.; Benitez, V.H.; Lozoya-Santos, J.d.-J.; Ramírez-Mendoza, R.A. Solar Irradiation Evaluation through GIS Analysis Based on Grid Resolution and a Mathematical Model: A Case Study in Northeast Mexico. Energies 2021, 14, 6427. [CrossRef]

13. Quiroga-Ocaña, G.; Montaño-Moreno, J.C.; Enríquez-Velásquez, E.A.; Benitez, V.H.; Félix-Herrán, L.C.; Lozoya-Santos, J.d.-J.; Ramírez-Mendoza, R.A. Computing and Assessment of Discrete Angle Positions for Optimizing the Solar Energy Harvesting for Urban Sustainable Development. Energies 2021, 14, 6441. [CrossRef] 